\title{
EDUCAÇÃO SOB CONTROLE: TENSÕES DO ACESSO À EDUCAÇÃO SUPERIOR
}

Ana Claudia Ferreira Rosa ${ }^{1}$

Arlete Maria Monte de Camargo ${ }^{2}$

\section{INTRODUÇÃO}

No momento atual de recrudescimento das políticas neoliberais alavancada pelo avanço da direita no Brasil e no mundo se propagam discursos que evocam a necessidade de depuração do ambiente educacional de uma ideologia de esquerda. Neste cenário, visualizamos claro retrocesso nas políticas educacionais em curso, seja na educação básica, seja na educação superior. Processo em que o discurso e os instrumentos regulatórios se retroalimentam alterando a realidade.

O estudo é parte da pesquisa adstrita ao Programa de Pós-Graduação em Educação do Instituto de Ciências da Educação da Universidade Federal do Pará para produção de tese que centraliza a educação superior, mormente a curricularização da extensão nos cursos de licenciaturas, e pautamos a investigação do problema a partir da seguinte questão: Qual o papel da regulação no controle ao acesso à educação superior e aos conhecimentos culturalmente produzidos?

Ao anunciar o problema ressaltamos um duplo viés da regulação: se, por um lado a regulação age no sentido de controlar o acesso à educação e os conhecimentos, de outro modo, pode atuar no sentido de ampliar esses acessos, em concordância com os interesses hegemônicos vigentes, o que explica, por exemplo, o processo de massificação da educação escolarizada sem alteração da estrutura social, econômica e política.

Compreendemos que a educação institucionalizada tem sido historicamente utilizada como instrumento de sustentação de hegemonia da classe dominante, ela tem sido controlada/regulada para servir à manutenção do sistema. Neste sentido, corroboramos Mészáros quando afirma que a educação serve: “[...] ao propósito de não só fornecer os conhecimentos e o pessoal necessário à

\footnotetext{
${ }^{1}$ Doutoranda pelo Programa de Pós-graduação em Educação pela Universidade Federal do Pará (UFPA)

2 Doutorado em Educação pela Universidade Federal de Minas Gerais (2004). Realizou estágio pós-doutoral na Universidade Federal do Rio Grande do Norte. Professora Titular Aposentada da Universidade Federal do Pará, atuando no Programa de Pós-Graduação em Educação, Linha Formação de Professores, Trabalho Docente Teorias e Práticas Educacionais na condição de professora voluntária.
} 
máquina produtiva em expansão do sistema do capital, como também gerar e transmitir um quadro de valores que legitima os interesses dominantes [...]”. (MÉSZÁROS, 2008, p. 35). Ressaltamos, no entanto, que esse processo não se faz pacificado, a contradição se apresenta em forma de luta de contra-hegemonia, de resistência reproduzidas nas tensões sociais.

A resistência ao retrocesso é protagonizada por diferentes setores da sociedade civil organizada entre as quais se encontram distintas associações científicas tais como: a Associação Nacional de Pós-Graduação e Pesquisa em Educação (Anped); a Associação Brasileira de Currículo (ABdC); e, a Associação Nacional pela Formação dos Profissionais da Educação (Anfope) ao lado delas, programas de pós-graduações também contribuem através do estudo sistemático de temas urgentes em aulas públicas, seminários, conferências, nos debates e na socialização dos estudos em publicações em periódicos nacionais e internacionais, entre outras formas de atuação.

No percurso para responder à questão-problema do estudo, a metodologia que adotamos prioriza a abordagem qualitativa do objeto, em uma análise documental com o uso da técnica da triangulação dos dados dos documentos nos três níveis da regulação, conforme Barroso (2006) e Cabrito (2011).

Ao considerar a macrorrealidade, visamos abarcar a totalidade, a historicidade, a contradição e a mediação, buscando compreender o objeto em sua singularidade pela compreensão das particularidades que o definem, em consonância com uma prática de pesquisa dialética. Neste sentido também que defendemos e praticamos o estudo de diferentes textos e discursos, compreendendo que “[...] textos devem ser lidos com e contra outros, ou seja, compreendidos em sua articulação ou confronto com outros textos" (SHIROMA; CAMPOS; GARCIA, 2005, p.432). Corroborando ainda o que defendem as autora citadass, buscamos compreender os documentos pelo que eles expressam e também pelo que eles ocultam.

Abordamos a educação superior como processo sistemático e intencional de produção e socialização dos conhecimentos em seus níveis mais elevados que se (re)produzem no cerne das lutas de classes em que o controle das políticas, dos currículos e da formação ocorre por processos de controle exógeno, hierárquico e vinculado aos interesses da classe dominante, confirmando uma hegemonia renitente e alienante. $\mathrm{O}$ conhecimento carrega as marcas da estrutura social desigual com a supremacia e os valores da classe dominante como classe hegemônica. Neste sentido, chega a ser tautológico afirmar que os valores regentes são os valores do mercado, do capital. Corroborando Marx e Engels (2009) afirmamos que: 
As idéias da classe dominante são em todas as épocas as idéias dominantes, ou seja a classe que é o poder material dominante da sociedade é, ao mesmo tempo, o seu poder espiritual dominante. [...] na medida, portanto, em que dominam como classe e determinam todo o conteúdo de uma época histórica, é evidente que o fazem em toda a sua extensão e, portanto, entre outras coisas, dominam como pensadores, como produtores de idéias, regulam a produção e a distribuição de idéias do seu tempo; que portanto, as suas idéias são as ideias dominantes da época. (MARX; ENGELS, 2009, p. 67)

Através da imposição dos próprios valores como universais, abstratos, neutros e científicos apresentados como pauta urgente e necessária, a parcela dominante da sociedade em atenção aos seus interesses de classe imprime o que Jameson, (1997 apud SHIROMA; CAMPOS; GARCIA, 2005) chamou de "hegemonia discursiva". A atenção a essa hegemonia sinaliza para a importância de buscar compreender os sentidos das produções dos discursos, pois estes, além de representarem a realidade produzem mudanças sociais conforme ressaltado por Fairclough (2001). Pautamo-nos ainda em Fairclough (2001) para delinear a seguir compreensão de hegemonia que nos referimos neste estudo:

Hegemonia é liderança tanto quanto dominação nos domínios econômico, político, cultural e ideológico de uma sociedade. Hegemonia é o poder sobre a sociedade como um todo de uma das classes economicamente definidas como fundamentais em aliança com outras forças sociais, mas nunca atingido senão parcial e temporariamente, como um 'equilíbrio instável. Hegemonia é a construção de alianças e a integração muito mais do que simplesmente a dominação de classes subalternas, mediante concessões por meios ideológicos para ganhar seu consentimento. Hegemonia é um foco de constante luta sobre pontos de maior instabilidade entre classes e blocos para construir, manter ou romper alianças e relações de dominação /subordinação, que assume formas econômicas, políticas e ideológicas. A luta hegemônica localiza-se em uma frente ampla, que inclui as instituições da sociedade civil (educação, sindicatos. família), com possível desigualdade entre diferentes níveis e domínios. (FAIRCLOUGH, 2001, p. 122)

A direção da sociedade seja pela força ou pelo consenso estabelece lugares, posições a serem alcançados pelos sujeitos, horizontes que podem ser caracterizados por limitação extrema ao acesso aos bens e serviços, como o ocorrido com o apartheid na África do Sul, mas também pode se caracterizar pelo controle através de um equilíbrio que busca equacionar tais acessos com os interesses do mercado, neste caso mais próximo da realidade da educação superior no Brasil na atualidade. Neste sentido o controle a que nos referimos que se faz medido por regulações pode ser observado pelo menos, por duas possíveis formas: primeiro pela contenção dos sujeitos na educação básica através, por exemplo, da inserção ou expectativa de inserção no mercado de trabalho pelo tipo de ensino profissionalizante em que o currículo se volta essencialmente para o atendimento à demanda do lucro e reprodução do capital; segundo, pelo controle também dos conhecimentos veiculados nos currículos dos cursos superiores aliado à uma concepção que está na gênese da educação superior brasileira reservada para a elite. 
Sobre a regulação, lembramos com Lessard (2000), que se trata de um termo polissêmico, aplicado a diferentes disciplinas o que exige especificar seu uso evitando dubiedade de interpretação. Diante da polissemia do termo o autor ressalta um aspecto que em nossa compreensão representa seu sentido mais geral, que expomos a seguir:

Elle renvoie à la fois à la recherche de l'équilibre dans un système d'action en mouvement, aux nécessaires adaptations d'un système dans ses rapports avec un environnement parfois source de perturbations (homéostasie), à des mécanismes de réduction de la variabilité des mouvements ou de correction des écarts par rapport à une norme ou une règle établie, au jeu de forces divergentes qui se rencontrent et dont le choc entraîne, à certaines conditions, l'établissement d'un compromis viable et apte à être reproduit, à la pression exercée sur des individus ou sur des unités pour qu'une certaine conformité des comportements se maintienne et se stabilise ${ }^{3}$. (LESSARD, 2000, p. 6-7)

Compreendemos que diante de inúmeras possibilidades de ação dos agentes políticos para o enfrentamento e superação dos desafios da gestão da coisa pública, a regulação persegue o equilíbrio, considerando padrões de referência que são produzidos através de análises comparativas de diferentes realidades, como se observa, por exemplo nos relatórios da Organização para Cooperação e Desenvolvimento Econômico (OCDE), do Banco Mundial e da Organização das Nações Unidas para a Educação, a Ciência e a Cultura (UNESCO). Busca-se a padronização de procedimentos minimizando diferenças e simplificando o controle dos comportamentos sob a pressão normativa coercitiva ou consensual.

$\mathrm{Na}$ estrutura do trabalho se priorizou inicialmente a abordagem da categoria regulação introduzindo conceito e acolhimento expresso nos documentos produzidos em âmbito nacional. Ressalta a normatização da hegemonia discursiva importada que vai dirigir ou controlar a sociedade através do controle dos processos e produtos sociais.

Na sequência aborda a educação superior ressaltando imbricada relação entre o público e o privado o que provoca alterações na configuração de acesso a esses serviços e desnuda a compreensão limitada e elitista dos governantes atualmente no exercício da coisa pública. Em seguida apresenta as considerações finais.

\footnotetext{
3 Refere-se tanto à busca de equilíbrio em um sistema de ação em movimento, às adaptações necessárias de um sistema em suas relações com um ambiente às vezes fonte de perturbações (homeostase), a mecanismos de redução da variabilidade do movimento ou correção de desvios de um padrão ou uma regra estabelecida, ao jogo de forças divergentes se encontram e cujo choque implica em certas condições, ao estabelecimento de um compromisso viável e apto a ser reproduzido, à pressão exercida sobre os indivíduos ou em unidades, de modo que uma certa conformidade de comportamentos seja mantida e estabilizada.(Tradução livre)
} 


\section{REGULAÇÃO: A INFLUÊNCIA DOS ORGANISMOS MULTILATERAIS EXPRESSA NOS DOCUMENTOS NACIONAIS}

A organização do Brasil contempla a produção de políticas públicas a partir de uma ordenação indicativa de hierarquia na legislação nacional, neste sentido, a Constituição Federal estabelece entre as competências privativas da união a de "legislar sobre diretrizes e bases da educação nacional" (BRASIL, 1988, art. 22 XXIV) e, a partir dessas diretrizes outras que se submetam a elas podem ser formalizadas, através da competência concorrente da União, dos Estados e do Distrito Federal, entre essas competências concorrentes constam a "educação, cultura, ensino, desporto, ciência, tecnologia, pesquisa, desenvolvimento e inovação. (BRASIL, 1988, IX).

De acordo com a LDB n 9.394/96, art. 21, inc. I e II, a educação escolar é composta de dois níveis escolares: a educação básica e a educação superior. O art. 22 dispõe sobre a finalidade da educação básica, a lei em referência ressalta fornecer os meios para progredir em estudos posteriores, ocorre, no entanto, que posterior à educação básica há possibilidades de estudos que não significam exatamente a passagem de um nível a outro, a exemplo a educação profissional técnica de nível médio na forma subsequente, disposta no art. 36-B, inc. II da LDB vigente. Então, o acesso à educação superior requer condições que não se encontram amparadas como dever do Estado.

Reitera-se que a LDB foi publicada na década das reformas educacionais da década de 1990, na base de um corpo de conhecimentos construído na interface exógena-endógena. Neste contexto que as regulações, admitidas no ordenamento jurídico, passam a normatizar as ações dos agentes nacionais e locais, e sobre elas pairam tensões sociais configurando as relações de poder e as necessidades latentes da sociedade. A despeito dos múltiplos sentidos do termo regulação, Lessard pautando-se em Dupriez et Maroy, afirma:

[...] ces multiples sens peuvent être regroupés autour de trois principales acceptions: la régulation "systémique", qui comprend les actions ou rétroactions qui contribuent cà maintenir en équilibre et à assurer le fonctionnement correct d'un système, la régulation "institutionnelle ou politique", renvoyant à l'ensemble des règles, des conventions et des mécanismes de contrôle mis en ouevre par une autorité reconnue pour orienter les actions d'acteurs sur lesquels elle a une certaine autorité, et la régulation comme "action" de production de règles du jeu dans un champ d'action déterminét. (LESSARD, 2000, p. 7).

\footnotetext{
4[...] esses múltiplos significados podem ser agrupados em torno de três significados principais: a regulação "sistêmica", que inclui as ações ou feedbacks que contribuem para manter o equilíbrio e garantir o funcionamento correto de um sistema, a regulação "institucional ou político", referindo-se a todas as regras, convenções e mecanismos de controle implementados por uma autoridade reconhecida para orientar as ações dos atores sobre os quais ela tem uma certa autoridade, e a regulação como" ação " de produção das regras do jogo em um determinado campo de ação.(Tradução livre)
} 
A regulação se afirma em um tríplice sentido e abrangência, que parte de uma orientação macro para o micro espaço de decisões e ações: regulação no âmbito sistêmico; institucional ou político; e regulação como ação.

Barroso (2006) ao se reportar a hierarquia das regulações identifica três diferentes níveis que se complementam: “[...] a regulação transnacional, a regulação nacional e a microrregulação local”. (BARROSO, 2006, p. 44). O autor ressalta aspectos característicos desse nível de regulação a partir da seguinte definição:

\begin{abstract}
Por "regulação transnacional" eu quero significar o conjunto de normas, discursos e instrumentos (procedimentos, técnicas, materiais diversos, etc.) que são produzidos e circulam nos fóruns de decisão e consulta internacionais, no domínio da educação, e que são tomados, pelos políticos, funcionários ou especialistas nacionais, como "obrigação" ou "legitimação" para adaptarem ou proporem decisões ao nível do funcionamento do sistema educativo." (BARROSO, 2006, p. 44-45).
\end{abstract}

Os organismos multilaterais como o Banco Mundial, a OCDE e a Unesco, ao ultrapassarem as fronteiras com suas recomendações/orientações produzidas por relatórios de pesquisas que eles próprios idealizam em nível local, executam em diferentes países e avaliam por suas referências métricas, imprimem o teor das políticas educacionais de diferentes nações. Tais regulações são materializadas em diferentes tipos e formas normativas: leis, decretos, portarias e manuais, entre outros.

Observamos com Cabrito (2011), que a regulação materializa o exercício de poder, consistindo em:

[...] o modo como os portadores de autoridade coordenam, controlam e influenciam o sistema educativo e seus atores, por meio de regras, normas, pressões e constrangimentos, condicionando a ação daqueles atores em função dos objetivos políticos que perseguem. (CABRITO, 2011, p.187).

A materialização de uma hierarquia que se vincula profundamente com os ideais de uma dada sociedade, em determinado contexto histórico. Observamos que a ação do agente político, vinculada a um controle é necessária até como garantia de que o exercício do poder político se configure como uma prática discricionária, ao sabor da vontade e interesses pessoais. Neste sentido consideramos fundamental essa perspectiva da regulação que atua também na garantia do Estado Democrático de Direito, como o país se constitui, conforme artigo primeiro da Constituição Federal. Esta é a base em que se assentam as políticas e praticas internas e externas do Brasil.

$\mathrm{Na}$ esteira da relação externa fundamentando as políticas externas, Oliveira (2005) observa que a regulação das políticas públicas educacionais nos anos 1990 do século XX se deu em decorrência das reformas de Estado implementadas como tendência do mercado mundializado 
pautado no Estado mínimo. Nesse contexto o termo se estende do campo da economia e sociologia para outros campos conforme aduz a autora em questão:

\begin{abstract}
Embora tal termo seja amplamente utilizado como conceito no âmbito da economia e da sociologia, desde os primórdios dessas disciplinas, ele começa a vulgarizar-se a partir dos processos de privatização de empresas públicas, que ocorreram com as reformas de Estado implementadas nas últimas duas décadas do século passado e, no caso brasileiro, mais especificamente durante o governo do presidente Fernando Henrique Cardoso. Com a privatização de empresas estatais responsáveis por serviços prioritários, tais como energia elétrica, água, gás, telefonia, entre outros, são criadas as agências de regulação, que têm por objetivo justamente controlar a oferta $\mathrm{e} o$ atendimento às demandas da população por esses serviços. (OLIVEIRA, 2005, p. 755).
\end{abstract}

As reformas que muito se pautaram no discurso da ineficiência do Estado na prestação de serviços, embasaram a liberação das empresas públicas desse provimento direto. Nessa nova configuração, corroborando a autora, coube ao Estado se encarregar da garantia da continuidade da prestação de serviços sob condições adequadas, através da regulação. O Estado provedor dá lugar ao Estado regulador, que atua em um contexto de relação globalizada, estruturada em diferentes níveis de atuação. Neste sentido as políticas públicas nacionais ocorrem em referência à tendências mundiais privatistas direcionando a sociedade, em sentido hegemônico, pela ação das instituições locais e seus agentes.

No âmbito da regulação transnacional a colaboração ocorre através de recomendações expostas em relatórios que sucedem pesquisas realizadas entre países que se relacionam mediados pelos organismos multilaterais como o Banco Mundial, a OCDE, a Unesco entre outros. (BARROSO, 2006). A complementaridade externa ocorre em parte pela relação entre diferentes países que se vinculam sob acordos, tratados e convenções. Nessa relação, as condições desiguais entre os países determinam posições de quem regula e de quem é regulado.

Dentre os recentes marcos regulatórios que alteraram decisivamente a natureza do processo de formação na educação superior, e que colocou em pauta a internacionalização da educação superior, está o chamado Processo de Bolonha, cuja influência não se restringiu somente às instituições europeias, mas afetou a educação superior no mundo todo. Segundo Morgado (2009), o chamado Processo de Bolonha teve entre os seus principais objetivos:

[...] a edificação de um Espaço Europeu de Ensino Superior - que viabilize a internacionalização das universidades, facilite a mobilidade de alunos e docentes, promova a empregabilidade dos cidadãos europeus e concorra para o desenvolvimento económico, social e humano da Europa -, a consolidação e enriquecimento da cidadania europeia e o aumento da competitividade com outros sistemas de ensino do mundo (em particular os dos Estados Unidos e do Japão). (MORGADO, 2009, p. 50). 
A ampliação do sistema de educação superior e a concessão ao setor privado de funções e serviços que, tradicionalmente estiveram sob a esfera pública, intensificou o entendimento da educação como mercadoria, o que colidiu com a interpretação da educação como um bem público. (DIAS, 2003, p. 821), entendimentos em disputa na atualidade, como predominância do que entende a educação como um serviço possível de comercialização.

No viés das novas configurações que atendem a maior flexibilidade da educação como mercadoria assistimos ao aumento da possibilidade de oferta da Educação à Distância $(\mathrm{EaD})$ desde a educação básica até a educação superior incluindo a pós-graduação stricto sensu, conforme disposição da portaria 1.428 de 28 de dezembro de 2018, que normatizou a possibilidade de aumento de $20 \%$ para $40 \%$ da carga horária da EaD nos cursos presenciais; e, a internacionalização no sentido da transnacionalização, que Azevedo (2015 destacou como: “[...] a oferta transfronteiriça de ensino, presencial ou a distância, por intermédio de organizações transnacionais de serviços educacionais com finalidade de lucro.” (AZEVEDO, 2015, p. 87). Corroborando Azevedo, Maués e Souza (2018) ressaltam ainda que a transnacionalização da educação superior é um fenômeno deste século e que seus fins abrangem os campos econômicos, políticos e jurídicos.

A institucionalização nacional da regulação transnacional, no Brasil, é assegurada na Carta Magna vigente, a exemplo do disposto no artigo $5^{\circ}, \S 2^{\circ}$ cuja disposição determina que: "Os direitos e garantias expressos nesta Constituição não excluem outros decorrentes do regime e dos princípios por ela adotados, ou dos tratados internacionais em que a República Federativa do Brasil seja parte. (BRASIL, 1988). A Lei Maior do país acena para a necessária observação aos tratados aos quais se consigna como membro. No âmbito da educação nacional a ratificação dessa observância está expressa na LDB vigente, a Lei $n^{\circ}$ 9.394/96 que ratifica nos termos que destacamos a seguir.

A União, no prazo de um ano a partir da publicação desta Lei, encaminhará, ao Congresso Nacional, o Plano Nacional de Educação, com diretrizes e metas para os dez anos seguintes, em sintonia com a Declaração Mundial sobre Educação para Todos. (Brasil, 1996, Art. $87, \S 1^{\circ}$, grifos nossos).

Além da Constituição Federal de 1988 e da LDB de 1996 uma gama de documentos exemplifica a regulação externa, expressando explicitamente no corpo do texto como é o caso do documento que trata da Tabela de Classificação dos Cursos de Graduação da Educação Superior Brasileira intitulado: “Áreas de formação e treinamento da Cine-F 2013: manual que acompanha a Classificação Internacional Normalizada da Educação 2011”,

A Cine 1997, em conjunto com o Fields of Education and Training, manual elaborado pela Eurostat em parceira com a Unesco e a Organização para a Cooperação e Desenvolvimento Econômico (OCDE), foram usados como referencial metodológico para a reorganização da 
Tabela de Classificação dos Cursos de Graduação da educação superior brasileira, ocorrida no ano 2000 e realizada pelo Instituto Nacional de Estudos e Pesquisas Educacionais Anísio Teixeira (Inep). Para tanto, recorreu-se à metodologia delineada pelos organismos internacionais, tendo em vista a necessidade de o Inep prestar informações acerca de estatísticas educacionais brasileiras para compor diversos estudos e publicações internacionais comparativos, por meio de levantamentos de dados internacionais. Desse modo, fez-se necessária a adoção de metodologia que fosse compatível com fins de comparação de dados estatísticos no âmbito internacional. Em virtude disso, a cada curso brasileiro é atribuído determinado código, denominado código OCDE, o qual é adotado a fim de permitir a extração de informações de cursos também por áreas de conhecimento, além da comparabilidade de dados. (INEP, 2017)

O documento justifica a relação estabelecida a partir da necessidade de parâmetros comuns que permitam a comparabilidade. Em nosso entendimento, faz sentido a estabelecimento de parâmetros para uma análise que envolve diferentes países, no entanto, há que se levar em conta no estabelecimento destes, as diferentes condições materiais dos países em jogo. De outro modo, sem essa observação qualquer resultado poderá recair sobre a ação dos sujeitos e não do Estado, omitindo as condições em que esses atuam. Dessa responsabilização decorre o fenômeno pernicioso e atualmente em debate no discurso contra-hegemônico: a responsabilização exclusiva dos professores e sua formação ${ }^{5}$, por resultados não satisfatórios dos alunos em testes que medem a qualidade da educação.

A produção normativa no âmbito do país, ou seja, a regulação nacional é definida por Barroso (2006) como:

[...] o modo como as autoridades públicas (nesse caso o Estado e a sua administração) exercem a coordenação, o controlo e a influência sobre o sistema educativo, orientando através de normas, injunções e constrangimentos o contexto da acção dos diferentes actores sociais e seus resultados. (BARROSO, 2006, p. 50)

No estabelecimento da regulação local, afirmamos com o autor que há um “complexo jogo de estratégias, negociações e acções de vários actores, pelo qual as normas, injunções e constrangimentos da regulação nacional são (re)ajustadas localmente, muitas vezes de modo não intencional" (BARROSO, 2006, p. 56). Importante ressaltar que os (re)ajustes intencionais ou não intencionais produzem resultados que modificam ou ratificam posições, ao modo da práxis não intencional, que, de acordo com Sánchez Vázquez (2011) resulta da fusão das práxis individuais

\footnotetext{
${ }^{5}$ Sobre as tendências da formação docente alavancadas pelas reformas a partir de 1990, ver: TORRES, Rosa Maria. Tendências da formação docente nos anos 90. In WARDE, M. J. (Org.). Novas políticas educacionais: críticas e perspectivas. São Paulo, Programa de Estudos Pós-Graduados em Educação: História e Filosofia da Educação da Pontifícia Universidade Católica de São Paulo, 1998; (autor) 2012; OLIVEIRA, Dalila Andrade. A reestruturação do trabalho docente: precarização e flexibilização. Educação \& Sociedade, n. 89, 2004.
} 
intencionais e produzem resultados que não se apresentavam como finalidade das atividades individuais.

No sentido de apresentar a definição do menor dos três níveis da regulação, em concordância com Barroso (2006), lembramos que a microrregulação local é definida como:

[...] o processo de coordenação da acção no terreno que resulta do confronto, interacção ou compromisso de diferentes interesses, lógicas, racionalidades e estratégias em presença quer, numa perspectiva vertical entre "administradores" e "administrados", quer numa perspectiva horizontal, entre diferentes ocupantes dum mesmo espaço de interdependência (intra e inter organizacional) - escolas, territórios educativos, municípios, etc. (BARROSO, 2006, p. 5657)

No sentido de produzir resultados coerentes com um projeto de interesse social, observamos o espaço da microrregulação como às instituições educacionais de educação superior, ainda que possua uma autonomia mitigada pela posição menor que ocupa na hierarquia das regulações, elas constituem rico espaço de proposição e não somente de ação. Por isso a resistência é necessária contra o papel de executora quando decisões são impostas de fora. O espaço de refletir com o auxílio de referenciais coerentes em consonância com o compromisso e seriedade com a classe trabalhadora, como ação consciente pautada não apenas nos resultados como o faz a política gerencialista dominante na atualidade, mas na desmistificação dos fenômenos que condicionam os indicadores de resultados: números sobre os quais se determinam as políticas públicas e forçam a ação dos gestores às condições de adequação. Ressaltamos que em âmbito nacional também podemos observar três níveis de regulação que pode ser verificada, por exemplo, pela seguinte composição: Plano Nacional de Educação (PNE), Plano Estadual de Educação e Plano Municipal de Educação (PME).

\section{A EDUCAÇÃO SUPERIOR NO CENTRO DE INTERESSES HEGEMÔNICOS: O PÚBLICO E O PRIVADO EM DISPUTA}

“O capital é a potência econômica da sociedade burguesa, que domina tudo". (MARX, 2008, p. 289).

No decorrer deste século XXI vemos com perplexidade, mas também com resistência, a privatização da educação superior como parte de uma política neoliberal exacerbada que transmuta valores e transforma bens indisponíveis em serviços vendáveis e lucrativos e nesta perspectiva submetida a um discurso de que cabe a iniciativa privada e não ao Estado a prestação de serviços. 
Sob medida para venda a educação superior padece com um problema que acomete as políticas públicas para a educação básica, a saúde, a moradia e todas as políticas sociais: o desmonte dessas políticas pelo financiamento público da iniciativa privada, ou melhor dizendo, iniciativa público-privada, de tão imbricadas essa relação nos discursos oficiais. Neste contexto o acesso aos serviços educacionais é mediado pela contração e o pagamento direto entre o cidadão consumidor e a empresa e o Estado atua como o agente financiador e regulador, o que garante a condição do que Azevedo (2015) ressaltou (a partir de Saldaña e Burgarelli, 2015) como capitalismo "acadêmico sem riscos”. A materialização dessa (des)configuração das políticas sociais ocorre por diferentes vias, sendo a mais recente na área da educação, o "Future-se", proposta do governo atual que trata da autonomia administrativa e financeira das instituições de educação superior e se organiza em três eixos: 1- gestão, governança e empreendedorismo; 2- pesquisa e inovação; 3 - Internacionalização. Trata-se de um meio para normatizar/regular materializando o discurso em relação à educação superior: a seletividade do acesso via cobrança de mensalidades e o estreitamento da relação públicoprivado. Uma proposta que, sem meandros, imputa às universidades e à Rede Federal de Educação a responsabilidade na captação de recursos financeiros para a continuidade de seus serviços. O Estado se afasta de sua responsabilidade de prover os recursos financeiros e sob a hegemonia discursiva da autonomia universitária propõe entregar o patrimônio público para as Organizações Sociais (OS), gerida por agentes externos aos quadros de servidores públicos. (BRASIL, 2019)

A configuração da educação é produto e processo das relações sociais de educadores e agentes públicos vinculados a esfera governamental e de agentes de instituições não-governamentais em relações em que se subscrevem. Relações marcadas por contradições frutos de interesses e projetos antagônicos em disputa que tensionam os currículos entre: veicular conhecimentos e valores que assegurem a manutenção das classes sociais em distintos e distantes lugares mitigando as diferenças gritantes; ou, veicular conhecimentos que evidenciem as diferenças de classes sociais e suas causas e favoreçam a conscientização e as condições para superação das desigualdades aventadas.

Ademais diferentes concepções fundamentam o acesso nos dois diferentes níveis da educação escolar, como se extrai do art. $4^{\circ}$ da LDB: "IV - acesso público e gratuito aos ensinos fundamental e médio para todos os que não os concluíram na idade própria; V - acesso aos níveis mais elevados do ensino, da pesquisa e da criação artística, segundo a capacidade de cada um" (BRASIL, 1996). Tais diferenças indicam que a legislação educacional, no contexto das políticas públicas sociais, sob a influência das regulações tem tratado o acesso à educação superior (cursos sequenciais por campo de saber, graduação, pós-graduação, extensão) como um privilégio que depende “da capacidade de cada um”. Trata-se da continuidade de uma concepção ideológica de direito à educação que atravessa os 
séculos conforme podemos conferir com Cunha (1988), o qual lista três tipos de conexões entre a prática da escola e a ideologia, dos quais destacamos o tipo I a seguir:

\begin{abstract}
No início das sociedades capitalistas até o seu amadurecimento no século XIX, os sistemas escolares excluíam praticamente todos os trabalhadores. As escolas eram freqüentadas pelas classes dominantes e pelas camadas médias e somente as poucas escolas mantidas por entidades confessionais, a título de caridade, aceitavam filhos de trabalhadores, preferencialmente os órfãos e os abandonados. A França e a Inglaterra, até o início do século, são bons exemplos desse tipo. Os objetivos atribuídos às escolas eram distintos conforme as classes sociais a que atendiam. Umas escolas atendiam as elites políticas, empresariais, culturais, eclesiásticas, etc., e outras amparavam os "desvalidos'. (CUNHA, 1998, p. 113114)
\end{abstract}

Ressalta-se, neste aspecto o princípio do individualismo herança da doutrina liberal que, lembramos com Cunha "[...] reconhece as desigualdades sociais e os direitos que os indivíduos mais talentosos têm de ser materialmente mais compensados". (CUNHA, 1988, p. 33).

Recentemente lemos em matéria do dia 28 de janeiro de 2019 do Jornal Valor Econômico, a declaração do anterior ministro da Educação Ricardo Vélez Rodríguez (substituído no dia oito de abril, pouco mais de três meses na pasta, por Abraham Weintraub). O então ministro Vélez profere sua (in)compreensão do acesso a educação superior afirmando que: "As universidades devem ficar reservadas para uma elite intelectual, que não é a mesma elite econômica [do país]”. A universidade para a elite intelectual e a inserção no mercado de trabalho para os outros, os "não-elite". O jornal ressaltou o foco do então ministro, no ensino técnico como contenção ao acesso à educação superior: "Para o novo comandante do MEC, o retorno financeiro dos cursos técnicos é maior e mais imediato do que o da graduação, o que pode a diminuir a procura por ensino superior no Brasil". (VALOR ECONÔMICO, 28/01/2019). O ministro externou uma concepção histórica de que o acesso aos níveis mais elevados do conhecimento é projeto para alguns poucos privilegiados, excluídos desses privilegiados os trabalhadores. Contra esse projeto que aliena e segrega é preciso mobilizar esforços coletivos até porque a fala do então ministro representa a visão de um grupo hegemônico e não apenas de um sujeito que reproduz a ideologia de classe privilegiada.

Reiteramos o aspecto da regulação na convergência de interesses. Elas condicionam políticas de financiamento e se tornam cogentes perseguindo, conforme afirmação de Cabrito (2011) fins objetivos. A fala do ministro se relaciona a interesses de restrições do acesso à educação superior como tendência do governo atual sob a presidência de Jair Bolsonaro o que significa um retrocesso no processo de democratização do acesso a esse nível de ensino que vinha ocorrendo desde o governo do Presidente Luís Inácio Lula da Silva com prosseguimento no governo da Presidenta Dilma Roussef. 
A democratização dos governos Lula e Dilma pode ser observada no desenvolvimento dos programas e projetos conforme ressaltado por Veloso, Nogueira e Luz (2014) a seguir:

\begin{abstract}
Considerando o período do governo Lula e posterior governo Dilma, ambos pautados na defesa pela democratização do acesso, no que concerne a política de educação superior, evidenciamos o documento promulgado neste período o Plano de Desenvolvimento da Educação (PDE/2007) [...], com destaque para os programas descritos em seu documento: o Programa de Apoio à Planos de Reestruturação e Expansão das Universidades Federais (REUNI) o Programa Nacional de Assistência Estudantil (PNAES), as mudanças no Programa Universidade para Todos (PROUNI), e no Fundo de Financiamento ao Estudante do Ensino Superior (FIES). Em relação à educação profissional e tecnológica, nas ações para educação O PDE destaca a criação dos Institutos Federais de Educação Ciência e Tecnologia (IFET). No período do governo Dilma temos a instituição do Sistema de Seleção Unificada (SISU) política voltada ao ingresso na educação superior. (VELOSO; NOGUEIRA; LUZ, 2014, p. 38)
\end{abstract}

Na contramão do PDE a restrição ao acesso a educação superior no governo atual vem sendo programada inclusive pelo esvaziamento da educação básica, através de um currículo pouco abrangente, voltado ao atendimento do mercado. Neste viés caminha a proposta do Projeto de Lei $\mathrm{n}^{\circ}$ 11.279/2019. A análise do documento revela o retrocesso na educação nas instituições da Rede Federal de Educação Profissional, Científica e Tecnológica destacando-se a omissão no texto da prioridade do Ensino Médio Integrado (EMI) na educação profissional técnica nos Institutos Federais. Atualmente a prioridade está expressa na Lei $\mathrm{n}^{\circ}$ 11.892/2008, com a oferta de vagas para o EMI de no mínimo 50\% em cada período letivo, como um dos objetivos dos Institutos Federais. Tal omissão pode implicar no esvaziamento dos currículos dos cursos em tela, restringindo-os às disciplinas técnicas com duplo viés ideológico neoliberal: por um lado meramente voltado para a empregabilidade, ou seja, preparatório para o mercado de trabalho e de outra forma, uma contenção ao acesso à educação superior pela classe trabalhadora. Um atendimento à formação de mão-de-obra qualificada e rápida para alimentar o mercado.

O caráter de abstração de que são revestidas se pautam em finalidades que se quer atingir e na esfera das políticas educacionais no contexto das sociedades capitalistas tais finalidades se pautam nos interesses do mercado mundializado, na educação como mercadoria, na instituição escolar como lugar de qualificação do trabalhador e de formação cultural da elite dominante. Para tanto além das normas a regulação transnacional atua na implementação direcionada seja através da oferta de consultorias/formações seja na oferta dos materiais ou em ambos os setores.

A regulação segue na pós-graduação através do controle em quantidade e qualidade da produção acadêmica, provocando uma corrida sem ponto de chegada, uma corrida permanente para atender critérios necessários ao conceito positivo dos cursos, assegurar o vínculo docente nos programas, enfim manter o currículo lattes de docentes e discentes competitivo nos processos de 
bolsa. Sobre esse processo de "intensificação e produtivismo acadêmico" resultado das regulações. Sguissard e Silva Junior ressaltam: “[...] é uma ideologia pautada no pragmatismo, na utilidade e no economicismo, que leva à heterogestão institucional, tendo a geri-la, de um lado, o Estado, e, de outro, o mercado, pela mediação, predominantemente, do CNPq e da Capes”. (SGUISSARD; SILVA JUNIOR, 2018, p. 40)

Promover o acesso à educação superior é uma condição que se alinha aos fundamentos da emancipação humana mediada pela práxis revolucionaria, neste sentido concordamos com Lessa e Tonet: "Se os homens fazem a história, não há razões para fazê-la sob o domínio do capital e de suas alienações, não há razões que justifiquem a produção crescente de desumanidades." (LESSA e TONET, 2011, p. 116). Portanto, sustentando a necessidade de defesa do direito ao acesso à produção cultural em seu nível mais elevado ressaltamos dois aspectos: primeiro que o acesso e a permanência à universidade brasileira, instituição pensada pela elite e para a sua perpetuação como classe dirigente apresenta-se como desafio à classe trabalhadora, fato que explica os processos de contenção das vagas nesse nível de ensino, expressos, sobretudo, no aparato jurídico; segundo, que o mesmo aparato jurídico regulatório pode de outro modo, produzir as condições de acesso à educação superior. Destacamos tais aspectos para reiterar que a regulação em si é um conceito comum. De outro modo, a que ou a quem serve é o que lhe confere sentido de instrumento de poder sobre as relações sociais.

\section{CONSIDERAÇÕES FINAIS}

O acesso à educação superior tem se dado sob contingenciamento e tensões, tais características são marcas do embate de forças entre a imposição de uma cultura hegemônica dominante que utiliza a educação tanto como veículo de propagação de seus valores como bem ou propriedade de diferenciação de classe e de outro lado a resistência dos docentes à assunção passiva de um currículo imposto e na defesa do acesso a produção cultural sistematizada irrestrita.

No contexto atual o conflito de interesses é cada vez mais explícito, público e polarizado de forma mais direta e objetiva. De um lado a classe dominante em sua necessidade de recomposição hegemônica imprime ataques às conquistas da classe trabalhadora e propaga suas ideologias, cria fatos falseando a verdade ao modo das suas conveniências imediatas. Em outra ponta, a resistência persiste como defesa de direitos conquistados pela democratização do espaço público, pela qualificação do discurso, pelo acesso aos conhecimentos culturalmente produzidos. O referido acesso não se dá automaticamente com a conclusão de um curso superior, até porque nas tendências que se 
vinculam a este nível da educação os interesses de mercado definem um currículo para atender seus próprios interesses configurando o capitalismo acadêmico sem precedentes. Nestas contradições são produzidas as políticas públicas que se balizam no pretenso atendimento aos diferentes segmentos e à submissão a processos de regulação centrípeto, exógeno e hierárquico, e muitas vezes sob o manto de recomendação se apresentam como condição necessária ao fomento da pesquisa, do ensino e da extensão.

Portanto, consideramos que a democratização do acesso à educação superior e aos conhecimentos culturalmente produzidos seja estratégica para o fortalecimento da contra-hegemonia por possibilitar as condições de interpretação e transformação das condições que sustentam a sociedade de classes em bases tão desiguais.

\section{REFERÊNCIAS}

AZEVEDO, Mário Luiz Neves de. Transnacionalização e mercadorização da educação superior: examinando alguns efeitos colaterais do capitalismo acadêmico (sem riscos) no Brasil - a expansão privado-mercantil. Revista Internacional de Educação Superior (RIESup), Campinas, v. 1 n. 1 p. 86-102, jul./set. 2015.

BARROSO, J. O estado, a educação e a regulação das políticas públicas. Educ. Soc., Campinas, vol. 26, n. 92, p. 725751, Especial - Out. 2005. Disponível em:〈http://www.scielo.br/pdf/es/v26n92/v26n92a02.pdf>. Acesso em: 05 fev 2019.

BARROSO, J. O Estado e a Educação: A regulação transnacional, a regulação nacional e a regulação local. In: BARROSO, J. (org.). A regulação das políticas públicas de educação: espaços, dinâmicas e actores. Lisboa: Educa/Unidade de I\&D de Ciências da Educação, 2006.

BRASIL. Constituição da República Federativa do Brasil de 1988. Disponível em: <http://www.planalto.gov.br/ccivil_03/Constituicao/Constituicao.htm>. Acesso em 12 set. 2018.

BRASIL. Lei no 9.394 de 20 de dezembro de 1996. Lei de Diretrizes e Bases da Educação Nacional. Disponível em: <http://www.planalto.gov.br/ccivil_03/leis/L9394.htm>. Acesso em: 13 ago. 2018.

BRASIL. Lei no 11.892 de 29 de dezembro de 2008, sobre a criação dos Institutos Federais de Educação, Ciência e Tecnologia. Disponível em: <http://www.planalto.gov.br/ccivil_03/_ato2007-2010/2008/lei/111892.htm/.>. Acesso: 12 nov. de 2018.

BRASIL. Lei no 13.005, de 25 de junho de 2014. Aprova o Plano Nacional de Educação - PNE e dá outras providências. Diário Oficial da União, Ano, 2014, Seção 1 - Edição Extra de 26/06/2014

BRASIL. Portaria $n^{\circ}$ 1.428, de 28 de dezembro de 2018. Publicada. Diário Oficial da União, Ano $2018, \mathrm{n}^{\circ} 250$.

BRASIL. Projeto de Lei 11.279/2019. Disponível em: <https://www.camara.leg.br/proposicoesWeb/prop_mostrarintegra?codteor=1703735\&filename=PL+11279/2019>. Acesso em 26 fev. 2019.

BRASIL. FUTURE-SE. Projeto de lei $\mathrm{n}^{\circ}$, de de de 2019. Institui o Programa Institutos e Universidades Empreendedoras e Inovadoras - FUTURE-SE, e dá outras providências 
CABRITO, B. Políticas de regulação e mudanças recentes no ensino superior em Portugal. In: NETO, A. C.; NASCIMENTO, I. V.; CHAVES, V. J. (Org.). Política de expansão da educação superior no Brasil: democratização às avessas. São Paulo: Xamã, 2011, p. 187-204.

VELOSO, Tereza Christina Mertens Aguiar; NOGUEIRA; Patrícia Simone Nogueira;

LUZ, Jackeline Nascimento Noronha da. Políticas pública de acesso na educação Superior: uma análise a partir dos indicadores da realidade. In, SOUSA, Andréia da Silva Quintanilha; CAMARGO, Arlete Maria Monte de. (Organizadoras) Interfaces da educação superior no Brasil. Curitiba, PR: CRV, 2014.

CUNHA, Luiz Antonio. Educação e desenvolvimento social no Brasil.10 ed. Rio de Janeiro: Francisco Alves, 1988.

DIAS, Marco Antonio Rodrigues. Comercialização no ensino superior: é possível manter a ideia de bem público. Educação \&Sociedade. Campinas (SP), v. 24, n. 84, p. 817-838, set.2003.

FAIRCLOUGH, Norman. Discurso e Mudança social. Izabel Magalhães, coordenadora da tradução, revisão técnica e prefacio. Brasília: Editora Universidade de Brasília. 2001.

INSTITUTO NACIONAL DE ESTUDOS E PESQUISAS EDUCACIONAIS ANÍSIO TEIXEIRA. [INEP, 2017]. Áreas de formação e treinamento da Cine-F 2013: manual que acompanha a Classificação Internacional Normalizada da Educação 2011 / tradução Andreza J. Meireles. - Brasília : Inep, 2017.

LESSARD, Claude. Présentation du Dossier Nouvelles régulations et professions de l'éducation. Éducation et Sociétés, $n^{\circ}$ 6/2000/2 . Disponível em: 〈http://ife.ens-lyon.fr/publications/edition-electronique/education-societes/RE006-1.pdf> Acesso em:

MARX, Karl. Contribuição á Crítica da Economia Política. 2 ed. São Paulo: Expressão Popular, 2008

MARX, Karl; ENGELS, Friedrich. A ideologia alemã. Tradução de Álvaro Pina. São Paulo: Expressão Popular,

MAUÉS, Olgaíses Cabral SOUZA, Michele Borges de. A transnacionalização e a expansão da educação superior. Revista Educação em Questão, Natal, v. 56, n. 47, p. 151-173, jan./mar. 2018. Disponível em: <https://periodicos.ufrn.br/educacaoemquestao/article/view/14002> Acesso em: 29 ago. 2018.

MÉSZÁROS, Istvan. A Educação para além do capital. (trad.) Isa Tavares. 2 ed. São Paulo: Boitempo, 2008.

MORGADO, José Carlos. Processo de Bolonha e ensino superior num mundo globalizado. Educ. Soc., Campinas, vol. 30, n. 106, p. 37-62, jan./abr. 2009. Disponível em:< http://www.scielo.br/pdf/es/v30n106/v30n106a03.pdf.> Acesso em: Acesso em: 29 ago. 2018.

OCDE (2018), Relatórios Econômicos OCDE: Brasil 2018, OECD. Publishing, Paris. Disponível em: <https://www.oecd-ilibrary.org/economics/relatorios-economicos-ocde-brasil-2018/avaliacao-erecomendacoes_9789264290716-3-pt.>. Acesso em: 16 jul. 2019.

OLIVEIRA, Dalila Andrade. Regulação das políticas educacionais na América Latina e suas conseqüências para os trabalhadores docentes. Educ. Soc., Campinas, vol. 26, n. 92, p. 753-775, Especial - Out. 2005. Disponível em: <http://www.scielo.br/pdf/es/v26n92/v26n92a03.pdf> Acesso em: 05 fev 2019.

SÁNCHEZ VÁZQUEZ, Adolfo. Filosofia da Práxis. 2 ed. Buenos Aires: Consejo Latinoamericano de Ciências Sociais - Clacso: São Paulo Expressão Popular, Brasil, 2011.

SGUISSARDI, Valdemar; SILVA JÚNIOR, João dos Reis. O trabalho intensificado nas federais: pós-graduação e produtivismo acadêmico. 2. ed. Uberlândia: Navegando Publicações, 2018.

SHIROMA, Eneida; CAMPOS, Roselane Fátima; GARCIA, Rosalba Maria Cardoso. Decifrar textos para compreender a política: subsídios teórico-metodológicos para análise de documentos. Perspectiva, Florianópolis, v. 23, n. 02, p. 427 446, jul./dez. 2005.

LESSA, Sérgio; TONET, Ivo. Introdução à Filosofia de Marx. 2 ed. Expressão Popular. São Paulo, 2011. 
VALOR ECONÔMICO. 'Ideia de universidade para todos não existe', diz ministro da Educação. Matéria de Hugo Passareli com Ministro da Educação Ricardo Vélez Rodríguez. Publicada em 28/01/2019. Disponível em: <https://www.valor.com.br/brasil/6088217/ideia-de-universidade-para-todos-nao-existe-diz-ministro-da-educacao>.

Acesso em 24 mar. 2018.

\section{EDUCAÇÃO SOB CONTROLE: TENSÕES DO ACESSO À EDUCAÇÃO SUPERIOR}

RESUMO: O estudo tem por objetivo compreender como a regulação da educação incide sobre o acesso à educação superior. Parte-se do seguinte problema: Qual o papel da regulação no controle do acesso à educação superior e aos conhecimentos culturalmente produzidos? A metodologia prioriza a análise documental e considerou as mudanças provocadas tanto por inserção quanto por omissão de diretrizes nos documentos pesquisados. Os resultados indicam que o acesso à educação superior se dá sob tensões de projetos societários, políticos e alavancados por interesses de atendimento ao mercado e que as mudanças do cenário se materializam via regulações que agem normatizando oficialmente o controle aos níveis mais elevados do conhecimento ampliando ou restringindo o referido acesso.

PALAVRAS-CHAVE: Acesso; Educação Superior; Regulação.

\section{EDUCATION UNDER CONTROL: VOLTAGES OF ACCESS TO COLLEGE EDUCATION}

ABSTRACT: The study aims to understand how education regulation affects access to higher education. The following problem arises: What is the role of regulation in controlling access to higher education and culturally produced knowledge? The methodology prioritizes document analysis and considered the changes caused by both insertion and omission of guidelines in the researched documents. The results indicate that access to higher education is under the stress of societal, political projects and leveraged by market service interests and that changes in the scenario materialize via regulations that act officially regulating control at the highest levels of knowledge by expanding or restricting said access.

KEYWORDS: Access; College education; Regulation

\section{EDUCACIÓN BAJO CONTROL: VOLTAJES DE ACCESO A LA EDUCACIÓN SUPERIOR}

RESUMEN: El estudio tiene como objetivo comprender cómo la regulación educativa afecta el acceso a la educación superior. Surge el siguiente problema: ¿Cuál es el papel de la regulación en el control del acceso a la educación superior y al conocimiento producido culturalmente? La metodología prioriza el análisis de documentos y considera los cambios causados tanto por la inserción como por la omisión de pautas en los documentos investigados. Los resultados indican que el acceso a la educación superior está bajo el estrés de los proyectos sociales y políticos y está apalancado por los intereses de los servicios de mercado y que los cambios en el escenario se materializan a través de regulaciones que actúan oficialmente regulando el control en los niveles más altos de conocimiento al expandir o restringiendo dicho acceso.

PALAVRAS CLAVE: Acceso; Educación universitaria; Reglamento

Submetido em Julho de 2019

Aprovado em Novembro de 2019

Revista Teias v. 20 • n. 59 • out/dez 2019 • Outras epistemologias e metodologias nas investigações sobre currículo 282 